\title{
ANALISIS RHEOLOGI LUMPUR LIGNOSULFONAT DENGAN PENAMBAHAN LCM BERBAHAN SERBUK GERGAJI, BATOK, DAN SEKAM BERBAGAI TEMPERATUR
}

\author{
Ryan Raharja' ${ }^{1)}$, Sugiatmo Kasmungin ${ }^{2)}$, Abdul Hamid ${ }^{3)}$. \\ ${ }^{1,2,3)}$ Prodi Magister Teknik Perminyakan, Fakultas Teknologi Kebumian \& Energi, Universitas Trisakti, Jakarta \\ Corresponding author email : raharjaryan85@gmail.com
}

\begin{abstract}
Abstrak
Kehilangan sirkulasi lumpur merupakan kejadian yang sering terjadi dalam proses pemboran. Hilang lumpur yang terjadi bisa saja sebagian dari lumpur pemboran dan bahkan kehilangan lumpur pemboran secara total. Pada percobaan ini kehilangan lumpur pemboran akan diteliti dalam skala laboratorium. Dengan penambahan LCM diharapkan berguna untuk menanggulangi hilangnya lumpur tersebut. Dengan mencoba mengalirkan lumpur pada media berpori yang telah ditentukan, kehilangan lumpur akan dilihat dari seberapa besar lumpur yang hilang dalam skala laboratorium yang dibuat. Kemudian lumpur yang dibuat ditambahkan LCM berupa serbuk gergaji, batok kelapa dan sekam padi dan diteliti seberapa besar pengaruh LCM dalam mengurangi kehilangan lumpur tersebut. Campuran macam LCM lumpur tersebut juga diuji pengaruhnya terhadap beberapa tingkatan temperatur antara lain temperatur $80^{\circ} \mathrm{F}, 190^{\circ} \mathrm{F}$ dan $300^{\circ} \mathrm{F}$, tentunya hal ini dilakukan untuk mendapatkan nilai sealing yang baik pada masing-masing LCM jika berada pada keadaan temperatur yang tinggi yang dikondisikan dengan kondisi sumur sebenarnya. Percobaan ini juga dilakukan untuk mengetahui filtrate loss yang terjadi pada berbagai macam campuran lumpur dengan LCM tersebut. Ketebalan mud cake yang terbentuk dalam pengukuran kehilangan filtrat juga diamati seberapa besar mud cake yang dihasilkan. Dan setelah itu reologi dari masing-masing lumpur tersebut juga diukur untuk menyimpulkan hasilnya.
\end{abstract}

Kata kunci: LCM, Sealing, Filtrate Loss, Rheologi

\section{Abstract}

Loss of mud circulation is an event that often occurs in the drilling process. The loss of sludge that occurred could be partly from drilling mud and even lost drilling mud completely. In this experiment the loss of drilling mud will be examined in a laboratory scale. With the addition of LCM it is expected to be useful to overcome the loss of the mud. By trying to drain the mud on the porous media that has been determined, the loss of mud will be seen from how much mud is lost in the laboratory scale made. Then the mud made was added by LCM in the form of sawdust, coconut shells and rice husks and examined how much influence the LCM had in reducing the loss of mud. The mixture of LCM sludge was also tested for its influence on several levels of temperature including temperatures of $80^{\circ} \mathrm{F}, 190^{\circ} \mathrm{F}$ and $300^{\circ} \mathrm{F}$, of course this was done to get a good sealing value at each LCM if it was in a high temperature condition which was conditioned by the condition of the actual well. This experiment was also conducted to determine the filtrate loss that occurs in various kinds of mud mix with the LCM. The thickness of mud cake that is formed in the measurement of filtrate loss is also observed how much mud cake is produced. And after that the rheology of each mud was also measured to conclude the results.

Key word: LCM, Sealing, filtrate loss, Rheology

\section{Pendahuluan}

Proses pemboran merupakan bagian dari usaha eksplorasi dan eksploitasi hulu migas. Tujuannya adalah menghubungkan reservoar migas ke permukaan. Ketika kegiatan ini berlangsung banyak sekali hambatan yang terjadi, salah satunya adalah kehilangan sirkulasi lumpur yang diakibatkan fluida tersebut masuk kedalam formasi. Percobaan ini dilakukan untuk mengetahui campuran LCM yang digunakan didalam lumpur yang sesuai dengan kebutuhan sealing capacity pada zona loss. Komposisi LCM yang tepat tentunya akan memberikan hasil yang baik dalam penanggulangan loss circulation yang disimulasikan pada skala laboratorium. Loss circulation material yang digunakan dalam percobaan ini adalah material fibrous yaitu serbuk gergaji, serta serbuk batok kelapa dan sekam padi.

Pemboran merupakan proses pembuatan lubang sesuai dengan kedalaman yang di targetkan. Proses ini dilakukan karena untuk memproduksikan hidrokarbon dari dalam reservoar ke atas permukaan bumi. Pada prosesnya banyak sekali hambatan dalam proses pemboran tersebut antara lain adalah hilangnya sirkulasi lumpur pemboran yang biasa di sebut Loss circulation. Kehilangan lumpur pemboran merupakan kejadian dimana lumpur yang digunakan untuk sirkulasi tersebut hilang di dalam sumur. Hilangnya lumpur bisa sebagian, parsial, dan kehilangan total. Kehilangan sirkulasi ini biasanya terjadi pada zona 


\section{ANALISIS RHEOLOGI LUMPUR LIGNOSULFONAT DENGAN PENAMBAHAN LCM BERBAHAN SERBUK GERGAJI, BATOK, DAN SEKAM BERBAGAI TEMPERATUR}

yang permeabel dimana pori dari batuan tersebut mampu menampung fluida pemboran sehingga fluida yang di sirkulasikan hilang sebagian maupun total.

Kehilangan lumpur pemboran merupakan kejadian yang berbahaya dan membutuhkan biaya yang tidak sedikit dalam penanggulangannya jika penanganannya dilakukan dengan tidak sesuai dengan prosedur penanganannya. Perancangan disain lumpur yang digunakan dalam proses pemboran pun harus disesuaikan dengan karakter lapisan yang akan ditembus. Perencanaan berat jenis dan sifat fisik lumpur lainnya harus diperhitungkan dengan baik agar proses pemboran berjalan aman dan lancar. Pada percobaan ini akan diteliti bagaimana pengaruh penambahan Loss Circulation Material terhadap kefektifan dalam mengurangi loss yang terjadi serta membandingkan rheologi lumpur tersebut seperti viskositas, gel stength, plastic viscocity, yield strength, dll.

\subsection{Kehilangan Lumpur Pemboran}

Pemboran merupakan kegiatan membuat lubang sampai dengan kedalaman yang ditentukan. Pada kegiatan pemboran sering terjadi masalah-masalah yang terjadi salah satunya adalah kehilanga sirkulasi lumpur pemboran. Kehilangan sirkulasi lumpur pemboran merupakan salah satu penyebab waktu yang tak produktif (NPT) dalam pemboran. Lost circulation didefinisikan sebagai kehilangan total dari fluida pemboran kedalam formasi (Messenger 1981). Di satu sisi, kehilangan sirkulasi kedalam reka han diakibatkan ketika tekanan fluida pemboran melebihi tekanan rekah formasinya (Howard and Scott, 1951) Laju kehilangan dalam bbl/jam sering kali digunakan untuk mendefinisikan kejadian lost menjadi rembesan (1-10 bbl/jam), parsial (10-500 bbl/jam) dan kehilangan keseluruhan $(>500 \quad \mathrm{bbl} / \mathrm{jam})$ (Nayberg and Pretty, 1986). Dengan mengidentifikasi lost, cara penanggulangan lost yang tepat dapat ditentukan.

\section{2 Densitas}

Densitas atau berat jenis didefinisikan sebagai berat persatuan volume dari padatan atau cairan, biasanya dinyatakan dalam ppg (pound per gallon). Berat jenis lumpur harus dikontrol agar dapat memberikan tekanan hidrostatik yang cukup untuk menahan tekanan formasi apabila tekanan hidrostatik terlalu kecil dapat mengakibatkan masuknya cairan formasi kedalam lubang bor dan terjadinya kick dan blow out, tetapi jika tekanan tersebut terlalu besar dan melebihi gradient rekah formasi maka akan menyebabkan formasi pecah dan lumpur hilang ke formasi. Oleh karena itu, berat jenis lumpur pemboran perlu direncanakan sebaikbaiknya dan disesuaikan dengan keadaan tekanan formasi. Di dalam teknik pemboran pada umumnya berat jenis lumpur dinyatakan juga dalam bentuk specific gravity (SG) yaitu perbandingan antara berat relatif suatu zat terhadap berat air pada volume zat itu.

Pengukuran berat jenis yang paling sederhana adalah menggunakan alat Mud Balance yaitu semacam alat penimbang yang satu batang ujungnya berskala dan ujung lainnya terdapat mangkuk tempat lumpur yang akan ditentukan densitasnya. Persamaan yang digunakan untuk menghitung densitas lumpur adalah:)

\subsubsection{Rheology dan Gel Strength}

Sifat-sifat fisik pemboran harus diatur sedemikian rupa agar tidak menimbulkan permasalahan pada saat proses pemboran berlangsung. Rheology dan gel strength memiliki peranan penting pada lumpur pemboran sehingga harus dijaga agar tidak terjadi perubahan-perubahan pada saat proses pemboran.

a. Viskositas

Viskositas suatu cairan adalah daya lawan terhadap gaya geseran yang bekerja pada suatu benda cair dimana benda cair tersebut dalam keadaan bergerak, dengan kata lain adalah suatu tahanan fluida terhadap suatu aliran. Dalam penggunaan lumpur pemboran viskositas harus diatur secara tepat, karena jika tidak diatur dapat menimbulkan masalah dalam proses pemboran. Viskositas yang terlalu tinggi akan menyebabkan:

1. Penetration rate turun

2. Pressure loss tinggi terlalu banyak gesekan.

3. Pressure surges yang berhubungan dengan Lost circulation dan swabbing yang berhubungan dengan blow out.

4. Sukar melepaskan gas dan cutting dari lumpur di permukaan.

Sedangkan viskositas yang terlalu rendah menyebabkan:

1. Pengangkatan cutting tidak baik

2. Material-material pemberat lumpur diendapkan

b. Plastic Viscosity (PV)

Plastic viscosity merupakan tahanan terhadap aliran yang disebabkan oleh gesekan antara sesama benda padat di dalam lubang bor dan merupakan 
salah satu parameter kenaikan padatan yang ada dalam lumpur.

\section{c. Yield Point (YP)}

Yield point merupakan sifat yang menunjukkan besarnya tekanan minimal yang harus diberikan kepada fluida agar fluida tersebut dapat bergerak mengalir. Tekanan ini disebabkan oleh gaya tarikmenarik antara partikel-partikel didalam lumpur. Tahanan terhadap aliran disebabkan oleh gaya elektrokimia antara padatan-padatan, cairan-cairan dan padatan-cairan yang dinyatakan dalam satuan lbs/100sqft yang dapat diukur dengan alat fann $V G$ meter. Nilai yield point yang tinggi dapat berfungsi dengan baik untuk membersihkan lubang bor secara maksimal, akan tetapi disisi lain akan mengakibatkan kehilangan tekanan yang besar.

\section{d. Gel Strength}

Di waktu lumpur bersirkulasi yang berperan adalah viskositas. Sedangkan diwaktu sirkulasi berhenti yang memegang peranan adalah gel strength. Lumpur akan menjadi agar atau menjadi gel apabila tidak terjadi sirkulasi, hal ini disebabkan oleh gaya tarik-menarik antara partikelpartikel padatan lumpur. Gaya menjadi agar inilah yang disebut gel strength. Di waktu lumpur berhenti melakukan sirkulasi, lumpur harus mempunyai gel strength yang dapat menahan cutting dan material pemberat lumpur agar tidak bergerak turun. Akan tetapi kalau gel strength terlalu tinggi akan membebani kerja pompa lumpur pemboran untuk memulai sirkulasi kembali. Gel strength biasanya diukur pada waktu 10 detik dan 10 menit dalam satuan $\mathrm{lb} / 100 \mathrm{ft}^{2}$.

\subsubsection{Filtration Loss}

Lumpur pemboran itu terdiri dari komponen padat dan komponen cair. Karena pada umumnya dinding lubang sumur mempunyai pori-pori, komponen cair dari lumpur akan masuk kedalam dinding lubang bor. Zat cair yang masuk ini disebut filtrate. Padatan dari lumpur akan menempel pada permukaan dinding lubang. Bila padatan dari lumpur yang menempel ini sudah cukup menutupi pori-pori dinding lubang, maka cairan yang masuk ke dalam formasi juga berhenti. Besarnya volume dari filtration loss ini ditentukan selama waktu pengukuran 30 menit dengan memberikan tekanan pada silinder sebesar 100 psi. Cairan yang masuk ke formasi pada dinding lubang bor akan menyebabkan akibat negatif, antara lain:

a. Dinding lubang akan lepas atau runtuh

Bila formasi yang dimasuki oleh zat yang masuk tersebut adalah air, maka ikatan antara partikel formasi akan melemah, sehingga dinding lubang cenderung untuk runtuh.

\section{b. Interpretasi dari logging tidak akurat}

Electric logging atau resistivity log mengukur resistivitas dari formasi cairan atau fluida yang dikandung oleh formasi tersebut. Kalau filtration loss banyak, maka yang diukur alat logging adalah resistivitas dari filtrate.

\section{c. Water blocking}

Filtrate yang berupa air akan menghambat aliran minyak dari formasi kedalam lubang sumur jika filtrate dari lumpur banyak.

\section{d. Differential sticking}

Seiring dengan banyaknya filtration loss maka mud cake dari lumpur akan tebal. Pada waktu sirkulasi berhenti ditambah lagi dengan berat jenis lumpur yang besar, maka drill collar yang terbenam didalam mud cake serta lumpur akan menekan dengan tekanan hidrostatik yang besar ke dinding lubang.

\section{e. Channeling pada semen}

Di waktu penyemenan, mud cake yang tebal kalau tidak dibersihkan akan menyebabkan ikatan antara semen dengan dinding lubang tidak baik.

\subsubsection{Mud Cake}

Mud cake adalah padatan lumpur yang tertinggal pada permukaan formasi yang berpori yang mana filtrat dari lumpur tersebut sudah masuk kedalam formasi. Besar ketebalan dari mud cake diharapkan tidak terlalu tebal yaitu sekitar 0,1-2 $\mathrm{mm}$. Hal ini diharapkan agar tidak mengganggu jalannya proses pemboran selanjutnya seperti masalah pipe sticking, dan filtrat yang masuk ke formasi tidak merusak dari formasi tersebut.

\subsubsection{Derajat Keasaman $(\mathrm{pH})$}

$\mathrm{pH}$ lumpur pemboran dipakai untuk menentukan tingkat kebasaan dan keasaman dari lumpur bor. $\mathrm{pH}$ dari lumpur yang dipakai berkisar antara 8,5 sampai 12, jadi lumpur pemboran yang digunakan adalah dalam suasana basa. Kalau lumpur bor dalam suasana asam maka cutting yang keluar dari lubang bor akan halus atau hancur, sehingga tidak dapat ditentukan batuan apakah yang ditembus oleh mata bor. Dengan kata lain sulit untuk mendapatkan informasi dari cutting. Selain dari pada itu peralatan-peralatan yang dilalui oleh lumpur saat sedang sirkulasi atau tidak mudah berkarat. Alat yang digunakan untuk mengukur $\mathrm{pH}$ lumpur adalah sebagai berikut: 


\section{ANALISIS RHEOLOGI LUMPUR LIGNOSULFONAT DENGAN PENAMBAHAN LCM BERBAHAN SERBUK GERGAJI, BATOK, DAN SEKAM BERBAGAI TEMPERATUR}

a. $\mathrm{pH}$ indikator: Sering juga dikatakan kertas lakmus atau $\mathrm{pH}$ paper.

b. $\mathrm{pH}$ meter: Dengan mencelupkan alat $\mathrm{pH}$ meter maka akan diketahui berapa $\mathrm{pH}$ dari lumpur tersebut.

\section{Metodologi}

Pada penelitian kali ini metode penelitian akan diawali dari proses persiapan alat dan bahan kemudian dilanjutkan dengan pembuatan lumpur dasar dan pengukuran dilakukan dengan berbagai tingkatan temperatur yang telah ditentukan. Lalu mengevaluasi lumpur mana yang menunjukkan hasil yang terbaik. Berikut gambar 1 adalah diagram alir metode penelitian analisis.

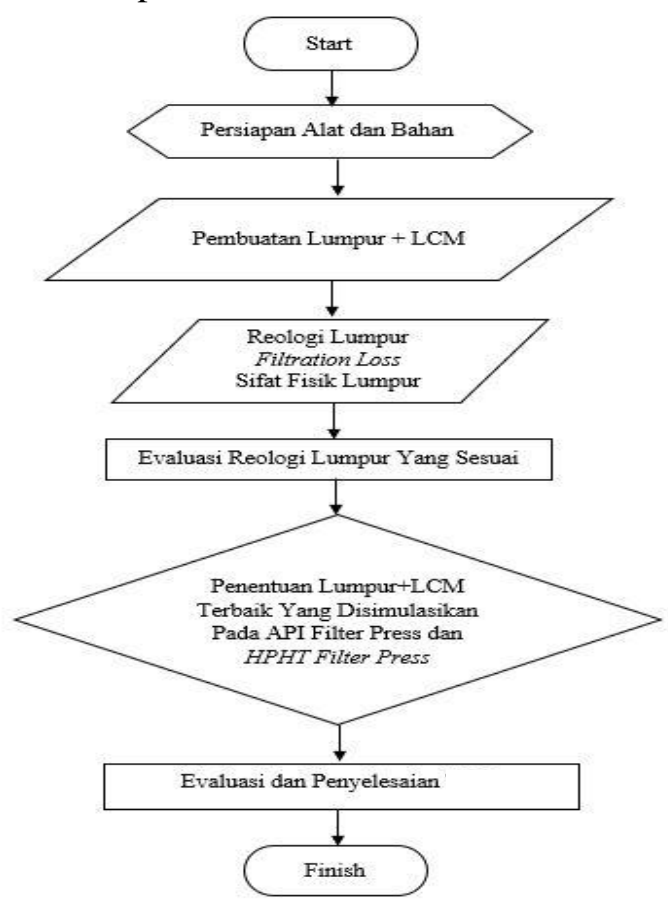

Gambar 1. Diagram Alir Metode Penelitian

Analisis kehilangan filtrat dan kehilangan lumpur didapatkan dengan melakukan pengujian dilaboratorium.

\section{Hasil \& Pembahasan}

Lumpur didalam proses pemboran memiliki peran penting dalam keberhasilan program pemboran. Akan tetapi keadaan bawah tanah yang tidak bisa dipastikan dapat menghambat dalam proses pemboran tersebut. Masalah yang sering dihadapi adalah kehilangan lumpur. Dalam penanggulangannya dapat dilakukan dengan berbagai macam cara seperti menambahkan loss circulation material (LCM) ke dalam campuran lumpur untuk mengurangi kehilangan lumpur tersebut. Pada penelitian kali ini peneliti berusaha melakukan eksperimen tentang pengaruh penambahan berbagai macam material LCM organik kedalam lumpur yang didisain untuk melihat pengaruh yang terjadi pada lumpur tersebut terhadap material LCM yang ditambahkan dengan komposisi berat yang ditambahkan. LCM yang digunakan adalah serbuk gergaji, batok kelapa dan sekam padi dengan penambahan sebesar 2, 5 dan 10 gram. Untuk mempermudah, lumpur akan dinamai berdasarkan kandungan yang ada pada masing-masing lumpur yaitu:

Lumpur 1 : lumpur dasar

Lumpur 2A : lumpur dasar ditambahkan serbuk gergaji 2 gram

Lumpur 2B : lumpur dasar ditambahkan serbuk gergaji 5 gram

Lumpur 2C : lumpur dasar ditambahkan serbuk gergaji 10 gram

Lumpur 3A : lumpur dasar ditambahkan sekam padi 2 gram

Lumpur 3B : lumpur dasar ditambahkan sekam padi 5 gram

Lumpur 3C : lumpur dasar ditambahkan sekam padi 10 gram

Lumpur 4A : lumpur dasar ditambahkan batok kelapa 2 gram

Lumpur 4B : lumpur dasar ditambahkan batok 


\section{kelapa 5 gram}

Lumpur 4C : lumpur dasar ditambahkan batok kelapa 10 gram

Penelitian juga dilakukan dengan mengamati perubahan yang terjadi pada beberapa tingkatan temperatur untuk menyesuaikan dengan kondisi lubang bor. Tingkatan temperatur yang digunakan pada percobaan ini adalah sebesar $80^{\circ} \mathrm{F}, 190^{\circ} \mathrm{F}$ dan $300^{\circ} \mathrm{F}$. Dalam melakukan percobaan diperlukan juga nilai standar spesifikasi sebagai acuan untuk sebuah bahan cocok atau tidak untuk digunakan.

\subsection{Pengukuran Pada Temperatur $8^{\circ} \mathrm{F}$}

Pengukuran disuhu ini disesuaikan dengan kondisi ruang sebagai temperatur terendah pada percobaan ini.

\subsubsection{Pengukuran Parameter Lumpur Dasar Pada Temperatur $80^{\circ} \mathrm{F}$}

Nilai dari parameter-parameter fisik lumpur dasar pada temperatur $80^{\circ} \mathrm{F}$ tersaji dalam tebel berikut.

Tabel 1. Rheologi Lumpur Dasar pada Temperatur $80^{\circ} \mathrm{F}$

\begin{tabular}{|l|c|}
\hline Mud Properties & Lumpur 1 \\
\hline Density (ppg) & 8.6 \\
\hline Viscosity (sec/quartz) & 54 \\
\hline Plastic Viscosity (cps) & 11 \\
\hline Yield Point (lbs/100 sqft) & 10 \\
\hline Gel Strength 10 sec (lbs/100 sqft) & 2 \\
\hline Gel Strength 10 min (lbs/100 sqft) & 9 \\
\hline API Water Loss 30 min, 100 psi (cc) & 8.4 \\
\hline Mud Cake (mm) & 0.5 \\
\hline pH Filtrate & 9.5 \\
\hline Mud Loss (\%) & 24 \\
\hline Mud Loss (ml) & 84 \\
\hline
\end{tabular}

Pengukuran pada percobaan yang dilakukan didapat besarnya nilai kehilangan lumpur yang terjadi pada lumpur dasar tersebut. Dengan demikian dapat dilakukan perbandingan selanjutnya dengan menambahkan LCM kedalam lumpur tersebut.

\subsubsection{Pengukuran Parameter Lumpur Dengan Tambahan Serbuk Gergaji Pada Temperatur $80^{\circ} \mathrm{F}$}

Penelitian berikutnya dilakukan dengan menambahkan LCM berupa serbuk gergaji. Pemilihan serbuk gergaji didasari dengan kemudahannya untuk didapat dan harga yang relatif murah dibanding LCM pabrikan. Penambahan berat dari LCM yang digunakan sejak awal telah ditentukan untuk memudahkan penelitian yaitu sebesar 2 gram, 5 gram dan 10 gram dan besar butiran yang digunakan sebesar 80 mesh untuk semua LCM yang dipakai dalam percobaan ini. Berikut adalah reologi dari lumpur yang telah ditambahkan dengan LCM organik serbuk gergaji dengan penambahan berat 2, 5 dan 10 gram.

Tabel 2. Rheologi Lumpur LCM Serbuk Gergaji pada Temperatur $80^{\circ} \mathrm{F}$

\begin{tabular}{|l|c|c|c|c|}
\hline Mud Properties & 1 & $2 \mathrm{~A}$ & $2 \mathrm{~B}$ & 2C \\
\hline Serbuk Gergaji (gr) & 0 & 2 & 5 & 10 \\
\hline Density (ppg) & 8.6 & 8.57 & 8.55 & 8.52 \\
\hline Viscosity (sec/quartz) & 54 & 53 & 59 & 65 \\
\hline Plastic Viscosity (cps) & 11 & 9 & 11 & 13 \\
\hline $\begin{array}{l}\text { Yield Point (lbs/100 } \\
\text { sqft) }\end{array}$ & 10 & 13 & 15 & 17 \\
\hline $\begin{array}{l}\text { Gel Strength 10 sec } \\
\text { (lbs/100 sqft) }\end{array}$ & 2 & 3 & 3.5 & 4 \\
\hline $\begin{array}{l}\text { Gel Strength 10 min } \\
\text { (lbs/100 sqft) }\end{array}$ & 9 & 10 & 9 & 9.5 \\
\hline $\begin{array}{l}\text { API Water Loss 30 min, } \\
\text { 100 psi (cc) }\end{array}$ & 8.4 & 7.8 & 7 & 6.6 \\
\hline Mud Cake (mm) & 0.5 & 0.75 & 1 & 1.2 \\
\hline pH Filtrate & 9.5 & 9.3 & 9.2 & 9 \\
\hline Mud Loss (\%) & 24 & 26 & 20 & 23 \\
\hline Mud Loss ml & 84 & 91 & 70 & 80.5 \\
\hline
\end{tabular}

Dari hasil percobaan terlihat terjadi perubahan pada sifat fisik dari lumpur yang dibuat. Dengan penambahan serbuk gergaji yang semakin banyak mempengaruhi nilai dari densitas, PV, dan YP. Dari percobaan ini terlihat bahwa kehilangan lumpur yang terjadi berkurang dengan seiring banyaknya penambahan serbuk gergaji.

\subsubsection{Pengukuran Parameter Lumpur Dengan Tambahan Batok Kelapa pada Temperatur $80^{\circ} \mathrm{F}$ \\ Penelitian berikutnya dilakukan dengan} menambahkan LCM berupa batok kelapa. Penambahan berat dari LCM yang digunakan sejak awal telah ditentukan untuk memudahkan penelitian yaitu sebesar 2 gram, 5 gram dan 10 gram dan besar butiran yang digunakan sebesar 80 mesh untuk semua LCM yang dipakai dalam percobaan ini. Berikut adalah reologi dari lumpur yang telah ditambahkan dengan LCM organik batok kelapa dengan penambahan berat 2, 5 dan 10 gram. 


\section{ANALISIS RHEOLOGI LUMPUR LIGNOSULFONAT DENGAN PENAMBAHAN LCM BERBAHAN SERBUK GERGAJI, BATOK, DAN SEKAM BERBAGAI TEMPERATUR}

Tabel 3. Rheologi Lumpur LCM Batok Kelapa pada Temperatur $80^{\circ} \mathrm{F}$

\begin{tabular}{|l|c|c|c|c|}
\hline Mud Properties & 1 & $3 \mathrm{~A}$ & $3 \mathrm{~B}$ & $3 \mathrm{C}$ \\
\hline Batok Kelapa (gr) & 0 & 2 & 5 & 10 \\
\hline Density (ppg) & 8.6 & 8.63 & 8.65 & 8.68 \\
\hline Viscosity (sec/quartz) & 54 & 63 & 67 & 73 \\
\hline Plastic Viscosity (cps) & 11 & 13 & 15 & 17 \\
\hline $\begin{array}{l}\text { Yield Point (lbs/100 } \\
\text { sqft) }\end{array}$ & 10 & 15 & 16 & 18 \\
\hline $\begin{array}{l}\text { Gel Strength 10 sec } \\
\text { (lbs/100 sqft) }\end{array}$ & 2 & 2.5 & 3 & 4 \\
\hline $\begin{array}{l}\text { Gel Strength 10 min } \\
\text { (lbs/100 sqft) }\end{array}$ & 9 & 7 & 9 & 10 \\
\hline $\begin{array}{l}\text { API Water Loss 30 } \\
\text { min, 100 psi (cc) }\end{array}$ & 8.4 & 9.2 & 8.6 & 8 \\
\hline Mud Cake (mm) & 0.5 & 1 & 1.25 & 1.5 \\
\hline pH Filtrate & 9.5 & 9 & 9 & 9 \\
\hline Mud Loss (\%) & 24 & 32.2 & 30 & 28 \\
\hline Mud Loss (ml) & 84 & 112.7 & 105 & 98 \\
\hline
\end{tabular}

Dari hasil percobaan terlihat terjadi perubahan pada sifat fisik dari lumpur yang dibuat. Dengan penambahan batok kelapa yang semakin banyak mempengaruhi nilai dari densitas, PV, dan YP.

\subsubsection{Pengukuran Parameter Lumpur Dengan Tambahan Sekam Padi Pada Temperatur $\mathbf{8 0}^{\circ} \mathbf{F}$}

Penelitian berikutnya dilakukan dengan menambahkan LCM berupa sekam padi. Penam-bahan berat dari LCM yang digunakan sejak awal telah ditentukan untuk memudahkan penelitian yaitu sebesar 2 gram, 5 gram dan 10 gram dan besar butiran yang digunakan sebesar 80 mesh untuk semua LCM yang dipakai dalam percobaan ini.

Tabel 4. Rheologi Lumpur LCM sekam padi pada temperatur $80^{\circ} \mathrm{F}$

\begin{tabular}{|l|c|c|c|c|}
\hline Mud Properties & 1 & $4 \mathrm{~A}$ & $4 \mathrm{~B}$ & $4 \mathrm{C}$ \\
\hline Sekam Padi (gr) & 0 & 2 & 5 & 10 \\
\hline Density (ppg) & 8.6 & 8.6 & 8.52 & 8.48 \\
\hline Viscosity (sec/quartz) & 54 & 57 & 62 & 71 \\
\hline Plastic Viscosity (cps) & 11 & 11 & 13 & 16 \\
\hline $\begin{array}{l}\text { Yield Point (lbs/100 } \\
\text { sqft) }\end{array}$ & 10 & 14 & 15 & 17 \\
\hline $\begin{array}{l}\text { Gel Strength 10 sec } \\
\text { (lbs/100 sqft) }\end{array}$ & 2 & 5 & 5 & 3 \\
\hline $\begin{array}{l}\text { Gel Strength 10 min } \\
\text { (lbs/100 sqft) }\end{array}$ & 9 & 12 & 13 & 14 \\
\hline $\begin{array}{l}\text { API Water Loss 30 } \\
\text { min, 100 psi (cc) }\end{array}$ & 8.4 & 7 & 6.2 & 5.8 \\
\hline Mud Cake (mm) & 0.5 & 0.5 & 0.75 & 1 \\
\hline pH Filtrate & 9.5 & 9.5 & 9.5 & 9.5 \\
\hline Mud Loss (\%) & 24 & 24.5 & 17.7 & 15 \\
\hline Mud Loss (ml) & 84 & 85.75 & 61.95 & 52.5 \\
\hline
\end{tabular}

Untuk mendapatkan ukuran yang diinginkan yaitu 80 mesh, sekam padi terlebih dahulu dihancurkan dengan cara ditumbuk hingga hancur dan kemudian diayak sehingga didapat ukuran yang ditentukan. Berikut adalah reologi dari lumpur yang telah ditambahkan dengan LCM organik sekam padi dengan penambahan berat 2, 5 dan 10 gram.

Dari hasil percobaan terlihat terjadi perubahan pada sifat fisik dari lumpur yang dibuat. Dengan penambahan sekam padi yang semakin banyak mempengaruhi nilai dari densitas, PV, dan YP. Nilai dari densitas semakin turun dengan penambahan sekam padi. Hal ini diakibatkan karena sekam padi memiliki nilai densitas lebih kecil dari pada lumpur. oleh sebab itu lumpur yang semakin banyak dtambahkan sekam padi nilai densitasnya semakin menurun.

Pada pengamatan yang dilakukan pada percobaan ini, dapat dibandingkan pengaruh yang terjadi ketika masing-masing LCM ditambahkan kedalam lumpur yang telah dibuat pada temperatur $80^{\circ} \mathrm{F}$. Terbukti bahwa serbuk gergaji, batok kelapa dan sekam padi dapat memberikan pengaruh terhadap sifat fisik dari lumpur dasar tersebut.

\subsection{Pengukuran Pada Temperatur $300^{\circ} \mathrm{F}$}

Percobaan berikutnya dengan memanaskan lumpur sampai dengan temperatur $300^{\circ} \mathrm{F}$ dan mengukur parameter fisiknya.

\subsubsection{Pengukuran Parameter Lumpur Dasar Pada Temperatur $300^{\circ} \mathrm{F}$}

Nilai dari parameter-parameter fisik lumpur dasar pada temperatur $300^{\circ} \mathrm{F}$ tersaji dalam tebel berikut.

Tabel 5. Reologi Lumpur Dasar pada Temperatur $300^{\circ} \mathrm{F}$

\begin{tabular}{|l|c|}
\hline \multicolumn{1}{|c|}{ Mud Properties } & Lumpur 1 \\
\hline Density (ppg) & 8.55 \\
\hline Viscosity (sec/quartz) & 38 \\
\hline Plastic Viscosity (cps) & 6 \\
\hline Yield Point (lbs/100 sqft) & 4 \\
\hline Gel Strength 10 sec (lbs/100 sqft) & 2 \\
\hline Gel Strength 10 min (lbs/100 sqft) & 3 \\
\hline $\begin{array}{l}\text { API Water Loss 30 min, 100 psi } \\
\text { (cc) }\end{array}$ & 13.2 \\
\hline Mud Cake (mm) & 1 \\
\hline pH Filtrate & 8.7 \\
\hline Mud Loss (\%) & 37 \\
\hline Mud Loss (ml) & 129.5 \\
\hline
\end{tabular}

Pengukuran pada percobaan yang dilakukan didapat besarnya nilai kehilangan lumpur yang terjadi pada lumpur dasar tersebut. Dengan demikian dapat dilakukan perbandingan selanjutnya dengan menambahkan LCM kedalam lumpur tersebut. 


\subsubsection{Pengukuran Parameter Lumpur dengan tambahan Serbuk Gergaji Pada Temperatur $300^{\circ} \mathrm{F}$}

Penelitian berikutnya dilakukan dengan menam-bahkan LCM berupa serbuk gergaji. Pemilihan serbuk gergaji didasari dengan kemudahannya untuk didapat dan harga yang relatif murah dibanding LCM pabrikan. Penambahan berat dari LCM yang digunakan sejak awal telah ditentukan untuk memudahkan penelitian yaitu sebesar 2 gram, 5 gram dan 10 gram dan besar butiran yang digunakan sebesar 80 mesh untuk semua LCM yang dipakai dalam percobaan ini. Berikut adalah reologi dari lumpur yang telah ditambahkan dengan LCM organik serbuk gergaji dengan penambahan berat 2, 5 dan 10 gram.

Tabel 4.6 Reologi Lumpur LCM Serbuk Gergaji Pada

\begin{tabular}{|l|l|l|l|l|}
\hline Mud Properties & 1 & $2 \mathrm{~A}$ & $2 \mathrm{~B}$ & $2 \mathrm{C}$ \\
\hline Serbuk Gergaji (gr) & 0 & 2 & 5 & 10 \\
\hline Density (ppg) & 8.55 & 8.5 & 8.5 & 8.47 \\
\hline Viscosity (sec/quartz) & 38 & 39 & 43 & 48 \\
\hline Plastic Viscosity (cps) & 6 & 3 & 5 & 7 \\
\hline Yield Point (lbs/100 sqft) & 4 & 7 & 10 & 12 \\
\hline $\begin{array}{l}\text { Gel Strength 10 sec } \\
\text { (lbs/100 sqft) }\end{array}$ & 2 & 3 & 3 & 3.5 \\
\hline $\begin{array}{l}\text { Gel Strength 10 min } \\
\text { (lbs/100 sqft) }\end{array}$ & 3 & 5 & 6 & 7 \\
\hline $\begin{array}{l}\text { API Water Loss 30 min, } \\
100 \text { psi (cc) }\end{array}$ & 13.2 & 12.4 & 11.6 & 11 \\
\hline Mud Cake (mm) & 1 & 1.25 & 1.5 & 1.75 \\
\hline pH Filtrate & 8.7 & 8.5 & 8.3 & 8 \\
\hline Mud Loss (\%) & 37 & 35 & 33 & 30 \\
\hline Mud Loss ml & 129.5 & 122.5 & 115.5 & 105 \\
\hline
\end{tabular}

Dari hasil percobaan terlihat terjadi perubahan pada sifat fisik dari lumpur yang dibuat. Dengan penambahan serbuk gergaji yang semakin banyak mempengaruhi nilai dari densitas, PV, dan YP. Dari percobaan ini terlihat bahwa kehilangan lumpur yang terjadi berkurang dengan seiring banyaknya penambahan serbuk gergaji.

\subsubsection{Pengukuran Parameter Lumpur dengan tambahan Batok Kelapa Pada Temperatur $300^{\circ} \mathrm{F}$}

Penelitian berikutnya dilakukan dengan menambahkan LCM berupa batok kelapa. Penambahan berat dari LCM yang digunakan sejak awal telah ditentukan untuk memudahkan penelitian yaitu sebesar 2 gram, 5 gram dan 10 gram dan besar butiran yang digunakan sebesar 80 mesh untuk semua LCM yang dipakai dalam percobaan ini. Berikut adalah reologi dari lumpur yang telah ditambahkan dengan LCM organik batok kelapa dengan penambahan berat 2, 5 dan 10 gram.

Tabel 7. Reologi Lumpur LCM Batok Kelapa Pada Temperatur $300^{\circ} \mathrm{F}$

\begin{tabular}{|l|l|l|l|l|}
\hline Mud Properties & 1 & $3 \mathrm{~A}$ & $3 \mathrm{~B}$ & $3 \mathrm{C}$ \\
\hline Batok Kelapa (gr) & 0 & 2 & 5 & 10 \\
\hline Density (ppg) & 8.55 & 8.57 & 8.6 & 8.63 \\
\hline Viscosity (sec/quartz) & 38 & 52 & 57 & 63 \\
\hline Plastic Viscosity (cps) & 6 & 9 & 11 & 13 \\
\hline Yield Point (lbs/100 sqft) & 4 & 12 & 14 & 16 \\
\hline $\begin{array}{l}\text { Gel Strength 10 sec } \\
\text { (lbs/100 sqft) }\end{array}$ & 2 & 2 & 3 & 3.5 \\
\hline $\begin{array}{l}\text { Gel Strength 10 min } \\
\text { (lbs/100 sqft) }\end{array}$ & 3 & 4 & 5 & 7 \\
\hline $\begin{array}{l}\text { API Water Loss 30 min, } \\
100 \text { psi (cc) }\end{array}$ & 13.2 & 13 & 12.4 & 12 \\
\hline Mud Cake (mm) & 1 & 1.5 & 1.7 & 2 \\
\hline pH Filtrate & 8.7 & 8 & 8 & 8 \\
\hline Mud Loss (\%) & 37 & 45.5 & 43.4 & 40 \\
\hline Mud Loss ml & 129.5 & 159.25 & 151.9 & 140 \\
\hline
\end{tabular}

Dari hasil percobaan terlihat terjadi perubahan pada sifat fisik dari lumpur yang dibuat. Dengan penambahan batok kelapa yang semakin banyak mempengaruhi nilai dari densitas, PV, dan YP, dan terlihat nilainya semakin bertambah seiring dengan penambahan berat LCM yang dicampurkan.

\subsubsection{Pengukuran Parameter Lumpur Dengan Tambahan Sekam Padi Pada Temperatur $300^{\circ} \mathrm{F}$}

Penelitian berikutnya dilakukan dengan menambahkan LCM berupa sekam padi. Penambahan berat dari LCM yang digunakan sejak awal telah ditentukan untuk memudahkan penelitian yaitu sebesar 2 gram, 5 gram dan 10 gram dan besar butiran yang digunakan sebesar 80 mesh untuk semua LCM yang dipakai dalam percobaan ini. Untuk mendapatkan ukuran yang diinginkan yaitu 80 mesh, sekam padi terlebih dahulu dihancurkan dengan cara ditumbuk hingga hancur dan kemudian diayak sehingga didapat ukuran yang ditentukan. Berikut adalah reologi dari lumpur yang telah ditambahkan dengan LCM organik sekam padi dengan penambahan berat 2,5 dan 10 gram.

Dari hasil percobaan terlihat terjadi perubahan pada sifat fisik dari lumpur yang dibuat. Dengan 


\section{ANALISIS RHEOLOGI LUMPUR LIGNOSULFONAT DENGAN PENAMBAHAN LCM BERBAHAN SERBUK GERGAJI, BATOK, DAN SEKAM BERBAGAI TEMPERATUR}

penambahan sekam padi yang semakin banyak mempengaruhi nilai dari densitas, PV, dan YP. Nilai dari densitas semakin turun dengan penambahan sekam padi. Hal ini diakibatkan karena sekam padi memiliki nilai densitas lebih kecil dari pada lumpur. oleh sebab itu lumpur yang semakin banyak dtambahkan sekam padi nilai densitasnya semakin menurun.

Tabel 8. Reologi Lumpur LCM Sekam Padi Pada

\begin{tabular}{|c|c|c|c|c|}
\hline \multicolumn{5}{|c|}{ Temperatur $300^{\circ} \mathrm{F}$} \\
\hline Mud Properties & 1 & $4 \mathrm{~A}$ & 4B & $4 \mathrm{C}$ \\
\hline Sekam Padi (gr) & 0 & 2 & 5 & 10 \\
\hline Density (ppg) & 8.55 & 8.55 & 8.49 & 8.45 \\
\hline Viscosity (sec/quartz) & 38 & 44 & 54 & 58 \\
\hline Plastic Viscosity (cps) & 6 & 6 & 9 & 11 \\
\hline Yield Point (lbs/100 sqft) & 4 & 10 & 12 & 14 \\
\hline $\begin{array}{l}\text { Gel Strength } \\
\text { (lbs/100 sqft) }\end{array}$ & 2 & 2.5 & 3 & 3 \\
\hline $\begin{array}{l}\text { Gel Strength } 10 \quad \mathrm{~min} \\
(\mathrm{lbs} / 100 \mathrm{sqft})\end{array}$ & 3 & 7 & 8 & 9 \\
\hline $\begin{array}{l}\text { API Water Loss } 30 \mathrm{~min} \text {, } \\
100 \mathrm{psi}(\mathrm{cc})\end{array}$ & 13.2 & 11.8 & 11 & 10.4 \\
\hline Mud Cake (mm) & 1 & 1 & 1.3 & 1.5 \\
\hline pH Filtrate & 8.7 & 9 & 8.7 & 8.9 \\
\hline Mud Loss (\%) & 37 & 33.7 & 31.4 & 28 \\
\hline Mud Loss ml & 129.5 & 117.95 & 109.9 & 98 \\
\hline
\end{tabular}

Pada pengamatan yang dilakukan pada percobaan ini, dapat dibandingkan pengaruh yang terjadi ketika masing-masing LCM ditambahkan kedalam lumpur yang telah dibuat pada temperatur $300^{\circ} \mathrm{F}$. Terbukti bahwa serbuk gergaji, batok kelapa dan sekam padi dapat memberikan pengaruh terhadap sifat fisik dari lumpur dasar tersebut.

\section{Kesimpulan}

Dari hasil penelitian yang dilakukan yaitu mengetahui pengaruh serbuk gergaji, batok kelapa dan sekam padi sebagai LCM pada lumpur pemboran dapat ditarik beberapa kesimpulan yaitu:

1. Penambahan berat LCM serbuk gergaji yang ditambahkan kedalam lumpur yang dibuat nyatanya mempengaruhi dari nilai rheologi lumpur yang terbentuk. Ini terbukti dari hasil yang didapat pada masing-masing bahan yang digunakan. Nilai PV mengalami perubahan menjadi 13 cps pada penambahan serbuk gergaji 10 gram, YP menjadi $17 \mathrm{lbs} / 100 \mathrm{sqft}$, dan nilai GS 10 detik naik menjadi 4 lbs/100sqft.

2. Temperatur mempengaruhi dari ketahanan LCM yang digunakan. Ketika dilakukan pada percobaan dan menaikkan temperaturnya, penurunan nilai parameter yang diukur menunjukkan penurunan. Seperti nilai PV dari sekam padi mengalami penurunan seiring bertambahnya temperatur, pada temperatur awal nilai PV sekam padi 10 gr menunjukkan nilai sebesar 16 cps, pada kenaikkan temperatur kedua dan ketiga mengalami penurunan masing-masing sebesar $14 \mathrm{cps}$ dan $11 \mathrm{cps}$.

3. Penambahan batok kelapa sebagai LCM kedalam lumpur malah menaikkan densitas dari lumpur yang lain. Penambahan batok kelapa sebesar 2 gr menaikkan densitas lumpur menjadi 8,63 ppg, penambahan sebesar 5 gr menaikkan densitas menjadi sebesar 6,65 ppg, dan penambahan batok kelapa sebanyak 10 gr menaikkan densitas menjadi 8,68 ppg pada temperatur $80^{\circ} \mathrm{F}$. Dikarenakan nilai dari densitas batok itu sendiri yang lebih tinggi dibanding dengan bahan lain yang digunakan maka mampu menaikkan densitas dari lumpur itu sendiri.

4. Hasil terbaik didapat pada campuran sekam padi 10 gr sebagai LCM karena nilai dari kehilangan sirkulasi yang terjadi menunjukkan nilai terkecil dibandingkan dengan bahan lain yang digunakan. Pada temperatur $80^{\circ} \mathrm{F}$ kehilangan lumpur pada sekam padi 10 gr mengalami $15 \%$ kehilangan lumpur. sedangkan serbuk gergaji memiliki besaran kehilangan sirkulasi sebesar $23 \%$ dan batok kelapa sebesar $28 \%$.

5. Temperatur juga mempengaruhi dari ketahanan LCM tersebut sebagai bahan penanggulangan loss dikarenakan seiring kenaikkan temperatur nilai dari kehilangan lumpurnya semakin bertambah. Pada sekam padi 10 gr pada temperatur $80^{\circ} \mathrm{F}$ kehilangan yang terbentuk sebesar $15 \%$, dan pada temperatur $190^{\circ} \mathrm{F}$ hasil yang didapat pada kehilangan lumpur sebesar $23 \%$ dan pada temperatur $300^{\circ} \mathrm{F}$ hasil yang didapat pada kehilangan lumpur tersebut sebesar $28 \%$ dari lumpur yang dibuat.

6. Kehilangan sirkulasi pada lumpur LCM sekam padi 10 gr pada temperatur $80^{\circ} \mathrm{F}$ memiliki nilai kehilangan sirkulasi terkecil yaitu hanya sebesar 15\% lumpur saja yang hilang, nilai ini masih sangat baik jika dibandingkan dengan nilai standar yang digunakan untuk pengukuran LCM temperatur rendah yaitu dengan mengharuskan nilai dibawah 30\% dari kehilangan lumpur.

\section{V.Daftar Pustaka}

Aadnoy, Bernt S., Belayneh, Mesfin, Arriado, Miguel, and Flateboe, Roar, 2008. Design of Well Barries To Combat Cirulation Losses. 
SPE 105449, Amsterdam, Netherland, 20-27 February.

Alsaba, Mortadha, and Nygaard, Runar,2014. Lost Circulation Materials Capability of Sealing Wide Fractures. SPE-170285-MS, Galveston, Texas, 10-11 September.

Alsaba, M., Magnar Nes, Olav , 2014. Laboratory Evaluation of Sealing Wide Fractures Using Conventional Lost Circulation Materials, SPE-170576-MS, Amsterdam, The Netherlands, 27-29 October.

Amanullah, M.D., 2016. Characteristics, Behavior and Performance of ARC Plug-A Date SeedBased Sized Particulate LCM. SPE182840-MS, Dammam, Saudi Arabia, 25-28 April.

El-Sayed, Mahmoud, Ezz, Ahmad, Aziz, Moataz, and Waheed, ArshaD, 2007. Successes in Curing Massive Lost-Circulation Problems With a New, Expansive LCM, SPE/IADC 108290, Cairo, Egypt, 22-24 October.

Ghalambor, Ali, Salehi, Saeed, P., Mojtaba, 2014. Integrated Workflow for Lost Circulation Prediction, SPE 168123, Lafayette, Lousiana, USA, 26-28 February.

Grant, Patrick, Lassus, Laurent, Savari, Sharath, L. Whitfill, Donald. 2016. Size Degradation Studies of Lost Circulation Materials in a Flow Loop. IADC/SPE-178774-MS, Fort Worth, Texas, USA, 1-3 March.

Hashmat, M.D., Sultan, Abdullah S., Rahman, Saifur, Hussain, Shakil, Asrof Ali, Shaikh, 2017. Flowing Gels For Loss Circulation Prevention, SPE-188103-MS, Dammam, Saudi Arabia, 24-27 April.

Howard, George C. And JR., P.P. Scott,1951. An Analysis and the control of Lost Circulation, Tulsa, Okla, February 19-21.

Junior, Adam T. Bourgoyne, Millheim, Keith K., Chenevert, Martin e., Junior, F. S. Young, 1986. Applied Drilling Engineering. First Printing, SPE, Richardson, Texas, USA.

Kulkami, Sandeep, Savari, Savari, Kumar, Arunesh, Jamison, Dale E, 2012. Novel Rheological Tool to Determine Lost Circulation Materials (LCM) Plugging Performance, SPE 150726, Cairo, Egypt, 20-22 Februari.
Kulkami, Sandeep, Savari, Savari, Jamison, Dale E., Maghrabi, Shadaab, Kumar, Arunesh, 2013. Normal Stress Rheology of Drilling Fluids and Potential in Lost Circulation Control. SPE 164617, Cairo, Egypt, 15-17 April.

Kulkami, Sandeep, Savari, Savari, Gupta, Nivika, 2016. Designing Lost Circulation Material LCM Pills for High Temperature Applications.SPE-180309-MS, Galveston, Texas, USA, 14-15 September.

Kulkami, Sandeep, Savari, Sharath, Jamisan, Dale E., Teke, Kushabhau D, 2014. Managing Suspension Characteristics of Lost Circulation Materials in a Drilling Fluid. SPE 170271, Galveston, Texas, 10-11 September.

Kulkami, Sandeep, Savari, Sharath, Jamisan, Dale E., Withfill, Donald L, 2010. Wellbore Strengthening: The Less-Studied Properties of Lost Circulation Materials. SPE 133484, Florence, Italy, 19-22 September.

Luzardo, J., Oliveira, E. P., Derks, P. W. J., Nascimento, R. Vega, Gramatges, A. Perez, and Valle, R., 2015. Alternative Lost Circulation Material for Depleted Reservoirs. OTC-26188-MS, Rio de Janeiro, Brazil, 27-29 October.

Miranda, C. R., Oliveira, J. L., Cavalcante, G. M. S., d'Almeida, A. R., 2017. Materials for Controlling Severe Lost Circulation Laboratory Evaluation. SPE-185582-MS, Buenos Aires, Argentina, 18-19 May.

Nayberg, T. M., Petty, B. R., 1986. Laboratory Study of Lost Circulation Materials for Use in Oil-Base Drilling Muds. SPE 14995, Amarillo, TX, April 6-8.

Nurhayati Syahri, Tjutju. 1988. Analisis Kimia 75 Jenis Kayu Dari Beberapa Lokasi Di Indonesia. Jurnal Penelitian Hasil Hutan Vol. 5 No. 1 pp. 6-11.

Pugersari, Dewi dkK, 2013. Eksperimen Pengembangan Produk Fungsional Bernilai Komersial Berbahan Baku Tempurung Kelapa Berusia Muda dengan Teknik Pelunakan. ITB J. Vis. Art\&Des, Vol.5, No.1, 74-91, Bandung, Indonesia.

Ristianingsih, Yuli dkk., 2014. Pengaruh Komposisi Sekam Padi dan Ampas Tebu Terhadap Karakteristik Kertas Dengan Proses Soda. 
Universitas Lambung Mangkurat, Banjarbaru, Kalimantan Selatan, Indonesia, Oktober.

Scott, Paul D., Beardmore, David H., Evans, Eddie, Frank, Krista D, 2012. Size Degradation of Granular Lost Circulation Materials. IADC/ SPE 151227, San Diego, California, USA, 6-8 March.
Valsecchi, Pietro. 2013. On the Shear Degradation of Lost Circulation Materials. SPE 163512, Amsterdam, 5-7 March.

Whitfill, Don., 2008. Lost Circulation Material Selection, Particle Size Distribution and Fracture Modeling with Fracture Simulation Software. IADC/SPE 115039, Jakarta, Indonesia, 25-27 August. 